---مجلة علوم الرافدين، المجلد 27، العدد 4 /عدد خاص بالمؤتمر العلمي الثالث لعلوم الحياة، ص 193-202، 2018---

تطبيق المؤشر الكندي (CCME WQI) لتقييم جودة المياه لأغراض الثرب: دراسة حالة جودة المياه

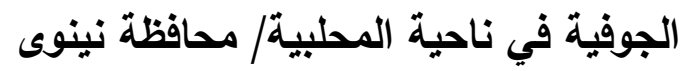

$$
\text { قسم علوم الحباة / كلية التزبية للعلوم الصرفة/ جلعيع الصفاوية الموصل }
$$

E-mail: alsaffawia@yahoo.com

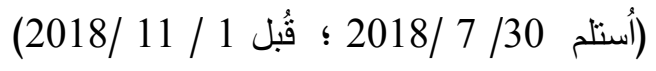

\title{
الملخص
}

تهدف الدراسة الحالية الى تطبيق الدليل الكندي لنوعية المياه (CCME WQI) على مياه اثثي عشر بئرا موزعة في ناحية المحلبية شمال غرب مدينة الموصل لتقيمها لأغراض الشرب، وقد هعت عينات مياه الابار شهريا من كل بئر ( من حزيران

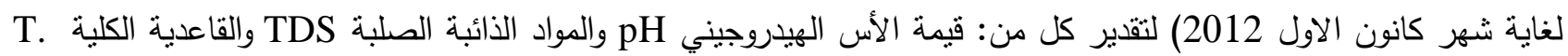

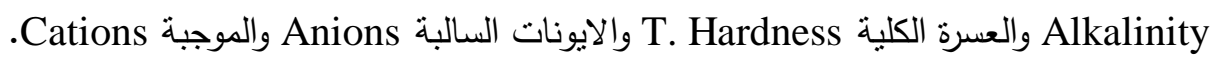
وتوصلت نتائج الدراسة الى ارتفاع تركيز بعض الصفات المقاسة، ولاسيما الاملاح الذائبة الصلبة وايونات الكالسيوم

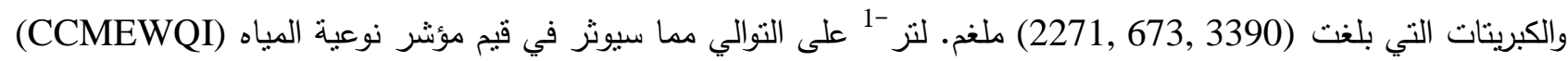

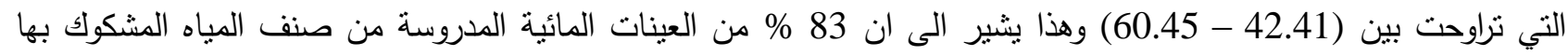
Marginal والبقية رديئة النوعية Poor quality للشرب وهذا التردي في نوعية المباه يعكس طبيعة التكوينات الجيولوجية التي مراتي تمر بها المياه، مما يتطلب بعض المعاملات البسيطة لها كعمليات التجميد والانصهار البطيء لتحسين نوعيتها قبل استخدامها للشرب.

الكلمات الدالة: نوعية مياه الابار ، الموديل الكندي CCMEWQI، ناحية المحلبية، العراق.

\section{Application of the CCME WQI to Evaluate Water Quality for Drinking Purpose: A Case Study for Groundwater Quality of Al-Mahalibiyah Sub District, Nineveh Province/ Iraq.}

\author{
Abdul-Aziz Y. Al-Saffawi \\ Department of Biology/College of Education for Pure Science/ University of Mosul
}

\begin{abstract}
The current study aims to applying the Canadian water quality model on water of twelve wells distributed in Al-Mahalibiyah sub district, north-west of Mosul, to be evaluated for drinking purposes, Monthly water samples were collected from each well, (From June to December 2012) to estimate the followings: PH, Total dissolved solids, Total Hardness, Total Alkalinity, Anions and Cations concentrations.

The results indicated a rise in some studied characters, especially Total dissolved Solid, Calcium and sulfate ions, that reached to $(33909.673,2271) \mathrm{mg} / \mathrm{L}$, respectively, which have a negative impact on the CCMEWQI values, which ranged between (42.41 - 60.45) and this indicates that $\% 83$ of the water samples were classified as Marginal water category and the rest were classified as Poor water quality of drinking, this deterioration in water quality reflects the nature of
\end{abstract}




$$
\text { عبدالعزيز يونس طليع الصفاوي }
$$

the geological formations that water passes through, which requires some treatments such as freezing and slow melting to improve their quality before drinking.

Keywords: Groundwater quality, CCMEWQI model, Al-Mahalibiyah Sub District.

\section{المقدمة}

" الماء هو الحياة Water is life" و" الصحة هي الثزوة Health is wealth" و "اهدار الثروة Waste to wealth" هو "العبث والاهمال بالموارد المائية حولنا التي ممكن ان تكون مدمرة للحياة والصحة والثزوة، إنّ توفير المياه الملائمة للاستخدام البشري أضحت من المشاكل الصعبة التي نواجه العالم في العديد من المناطق خاصة في دول العالم الثالث؛ اذ ان اعدادا كبيرة من الامراض التي تصيب الانسان تتنقل عن طريق المياه وتسبب مختلف أنواع الامراض حتى الخطيرة منها ، التي قد تسبب الموت منل الكوليرا والتيفوئيد والـ Shigellosis... الخ (الصفاوي والعساف، 2018)، وتتشير الدراسات الى حدوث اكثر من 3 مليون حالة وفاة سنويا بسبب استخدام مياه شرب غير أمينة وبخاصة امراض الاسهال لدى الاطفال (Reed et al., 2000)، وفي مالي الوقت الحاضر فإن الكثير من الثعوب الافريقية تعاني من نقص المياه النقية، إذ أن 18 مليون فرد في كينيا و 57 مليون فرد في نيجيريا لا يحصلون على المياه النقية، وان اكتر من 3100 طفل في كينيا و

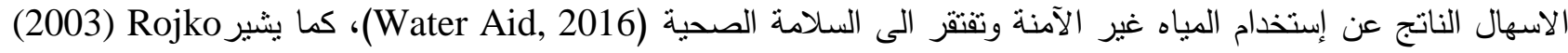
الى أن اكثر من 30\% من شعوب العالم الثالث بحاجة الى المياه النظيفة وان 875 مليون حالة اسهال تحدث كل عام بسبب عدم الإد سلامة مياه الثرب في هذه الدول (الصفاوي والمعاضيدي، 2018)، والحقيقة المرعبة لتوقعات . UNEP (2008) بإن ثلثي سكان العالم سيعانون من العجز المائي بحلول عام 2025 ؛ اذ ستعاني 25 دولة من العجز المائي في افريقيا لوحدها بمقدار ( 1.700 (هئي لكل فرد سنويا. ان استمرار التدهور البيئي قد يؤدي الى حدوث كارثة يصعب التغلب عليها، لذا فقد دعا الرأي العام الدولي الى تتبع المؤشرات التي تدل على تتاقص كميات المياه وزيادة التلوث فيها مع زيادة النوعية المجتمعية بكافة الوسائل الاعلامية

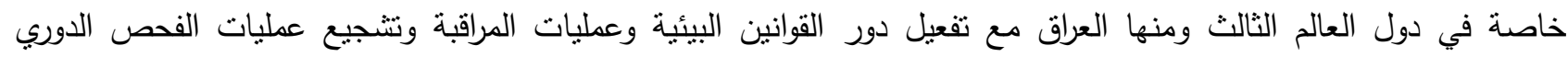
للمصادر المائية وتتبع مصادر التلوث للحد من انتشارها كذلك التوجه نحو ترشيد الاستهلاك المائي في كافة المجالات للحفاظ ولثان على هذه الثروة مع استخدام الطرائق الحديثة لتقييم نوعية المياه كاستخدام موديلات Models لتقييم نوعية المياه السطحية

والجوفية.

ان استخدام موديلات نوعية المياه WQI Models قد انتشرت بشكل كبير بعد اقتراح موديل رياضي من قبل Horton عام

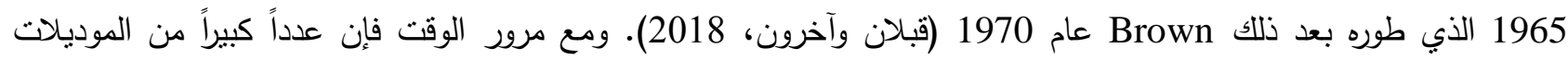
اقترحت وطورت بسبب قابلية الدليل على اعطاء قيمة مفردة تعكس التداخلات بين الاعداد الكبيرة من البيانات والصفات الخاصة

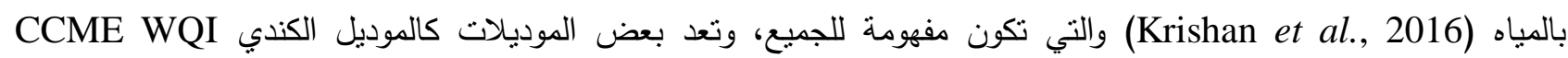
والموديل الرياضي الموزون WAWQI وموديل مؤسسة الصحة الوطنية NSFWQI) National sanitation Foundation CCME من اكثر الموديلات استخداما وشيوعا في العالم، ويتميز الموديل الكندي OWQI لنوعية المياه Oregon وموديل

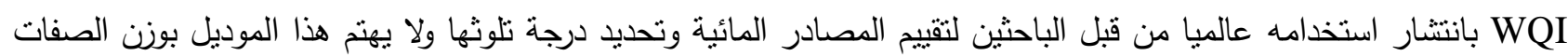
(Parameters)

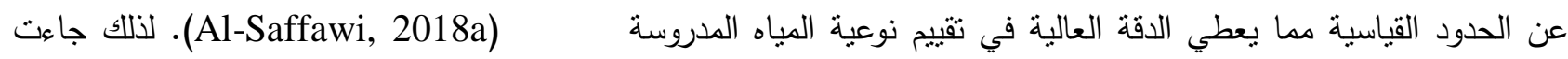
الدراسة بهدف تقييم مياه ابار ناحية المحلبية لاغراض الثرب باستخدام الموديل الكندي لتقييم نوعية المياه. 


\section{المواد وطرائق العمل}

درس البحثُ بعضَ الخصائص الفيزياوية والكيمياوية لبعض مصادر المياه الجوفية لناحية المحلبية التابعة لقضاء تلعفر / محافظة نينوى غرب مدينة الموصل؛ اذ تم تحديد 12 بئرا بصورة عشوائية في ناحية المحلبية كما موضح في الثكل (1) الذي يشير الى لى ابتعاد مصادر المياه للقرية عن التغذية من الانهار والمسطحات المائية، وتعد الآبـار المدروسة من النوع العميقة لتجاوز اعماقها 20 متر (Al-Saffawi, 2018b) واغلبها ذات طعم غير مستساغ ومر ، و (الجدول 1) يوضح بعض ونساه خصائص المياه المدروسة. تتميز منطقة الدراسة بوجود تكوين الفتحة الحاوية على املاح المتبخرات (الجبس الدولومايت) مما يؤدي الى تردي نوعية المياه المارة خلالها مسببة اضرارا اقتصادية عند استخدام مثل هذه المياه (السردار واخرون، 2018 ).

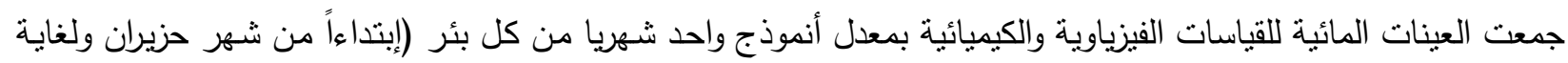
شهر كانون الاول 2012) باستخدام قناني من البولي اثيلين النظيفة حسب ما أشـار اليه (APHA, 1998)، اذ تم قياس الدالة الحامضية بجهاز الـ pHeter بعد نتظيم الجهاز بمحاليل متعددة البفر (9, 7, 4) والمواد الذائبة الصلبة بالطريقة الوزنية، كما تم قياس القاعدية الكلية ومسبباتها بالمعايرة مع حامض الكبريتيك القياسي والعسرة الكلية وأيونات الكالسيوم والمغنيسيوم بالمعايرة

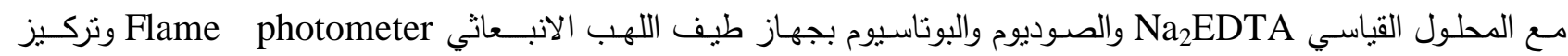

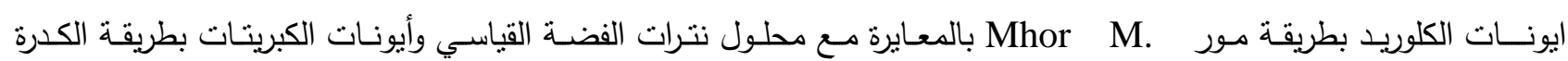
كما تم قياس الفوسفات بطريقة ( Stannous chloride Midmatric M.

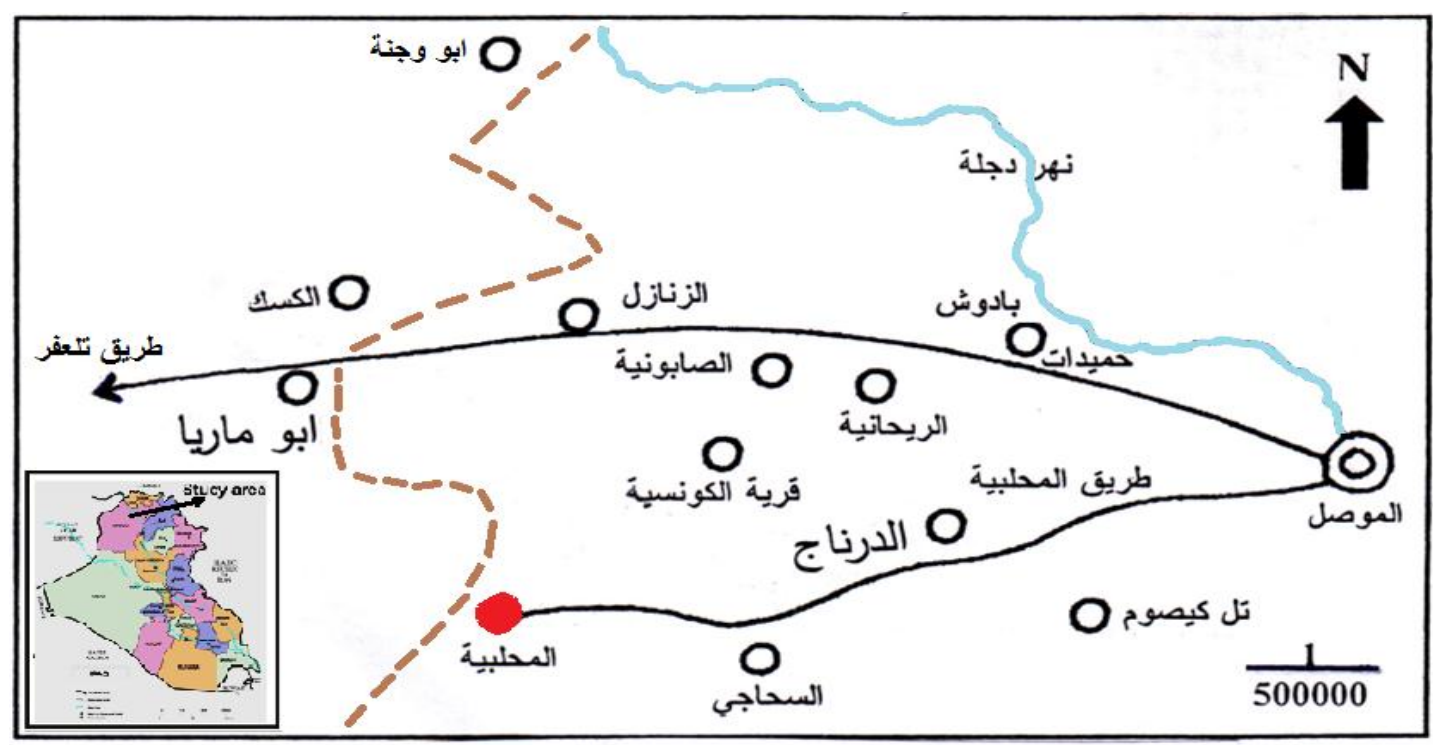

الشكل 1: منطقة جمـع عينات مياه الابـار من ناحية المحلبية 
عبدالعزيز يونس طليع الصفاوي

\begin{tabular}{|c|c|c|c|c|}
\hline الملاحظات & الاستخد/مات & العقى م & اسم صاحب البئر & $\begin{array}{l}\text { Well } \\
\text { NO } \\
\end{array}$ \\
\hline طعم غيرمستساغ ومر & يستخدم لكافة الاغر اض & 33 & عبدالكريم المصائد & 1 \\
\hline طعم غير مستساغ ومر & بستخدم لكافة الاغر اض & 30 & حسن المصائد & 2 \\
\hline طعم غير مستساغاغور & بستخدم لكافة الاغر اض & 28 & محمد طاهر & 3 \\
\hline طعم غير مستساغ ومر & يستخدم لكافة الاغر اض & 45 & |حمد عبود & 4 \\
\hline طعم غير مستساغاغومر & يستخدم لكافة الاغر اض & 38 & عبدالستار المصائد & 5 \\
\hline طعم غير مستساغ ومر & بستخدم لكافة الاغر اض & 17 & خضر جدوع & 6 \\
\hline طعم غير مستساغاغومر & يستخدم لكافة الاغر اض & 29 & خيري المصائد & 7 \\
\hline طعم غير مستساغ ومر & يستخدم لكافة الاغر اض & --- & فخري المصائد & 8 \\
\hline طعم غير مستساغ ومر & يستخدم لكافة الاغر اض & 33 & ناطق هاشم & 9 \\
\hline طعم غير مستساغ ومر & بستخدم لكافة الاغر اض & 33 & محمد خالد & 10 \\
\hline طعم غير مستساغ ومر & بستخدم لكافة الاغر اض & 30 & جاسم المصائد & 11 \\
\hline طعم غير مستساغ ومر & بستخدم لكافة الاغر اض & 32 & حربي المصائد & 12 \\
\hline
\end{tabular}

\section{CCME WQI حساب الاليل الكندي لنوعية المياه}

يتميز الموديل الرياضي الكندي لنوعية المياه بدقته العالية ويتم ايجاد قيم الدليل بحساب ثلاثة عوامل factors، وكما يلي لوكياه

:(Al-Saffawi, 2018c ; Salman et al., 2015)

المدى: تمثل النسبة المئوية للمتغيرات المتجاوزة للحدود القياسية مقارنة بالعدد الكلي للمتغيرات (ولو مرة واحدة خلال

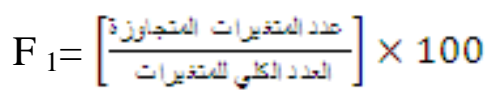

فترة الدراسة).

(frequency) F2

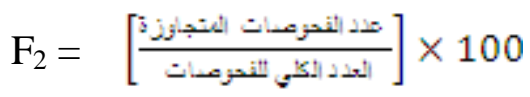

(Amplitude) F3 1.المرحلة الأولى :عدد مرات تجاوز التراكيز الفردية للحدود القياسية ويطلق عليها الانحراف (Excursion) وتحسب كما يأتي:

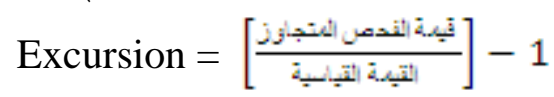

وفي حالة كون قيمة الاختبار المتجاوز اكبر من القيمة القياسية تحسب بقلب النسبة.

2.المرحلة الثانية: كمية مجموعة الاختبارات الفردية المتجاوزة وينت حسابها بجمع الانحرافات الفردية وقسمتها على العدد الكلي

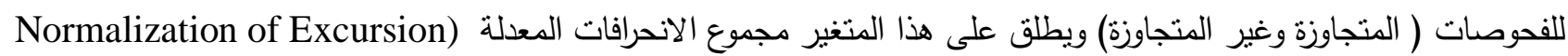

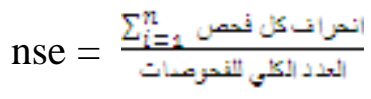

) ويرمز له (nse)

ويتم حساب السعة F F من المعادلة الآتية:

$F 3=\frac{n s e}{0.01 \text { nse }+0.01}$

وبعد ايجاد العو امل الثنلاثة يتم حساب الدليل الكندي من المعادلة الآتية:

$C C M E W Q I=100-\left[\frac{\sqrt{F 1^{2}+F 2^{2}+F 3^{2}}}{1.732}\right]$ 
الثابت 1.732 هو لتعديل نتيجة قيمة الدليل وجعلها محصورة بين 0.0 - 100.

وتصنف نوعية المياه الى خمسة اقسام (Kumar et al., 2014) كما في الجدول (2):

\begin{tabular}{|c|c|c|c|c|c|}
\hline \multicolumn{6}{|c|}{ الجدول 2: قيم نوعية المياه لتصنيف مياه الابار. } \\
\hline $44-0.0$ & $59-45$ & $79-60$ & $94-80$ & $100-95$ & WQI \\
\hline Poor & Marginal & Fair & Good & Excellent & التصنيف \\
\hline 5 & 4 & 3 & 2 & 1 & الدرجة \\
\hline
\end{tabular}

\section{النتائج والمناقشة}

لقيمة الاس الهيدروجيني تأثثر في نوعية مياه الري والثرب بسبب تأثيرها في توازن الكاربونات ومحتوى المياه من العناصر المعدنية (Al-Saffawi, 2018c)، وتنثير النتائج المبينة في (الجدول 3) الى التذبذب النسبي للقيم التي تراوحت بين (6.337.38) وان 52 \% من العينات المائية ضمن المدى الحامضي؛ اذ ان انخفاض القيم سيؤدي الى زيادة ذوبان العناصر المعدنية

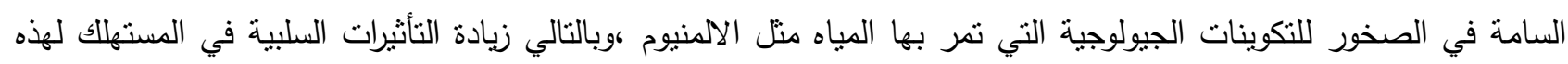

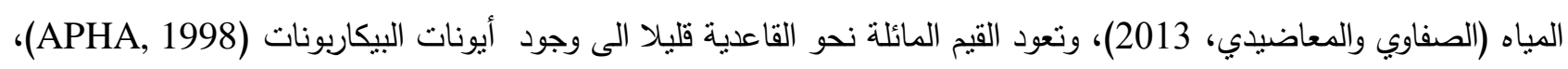

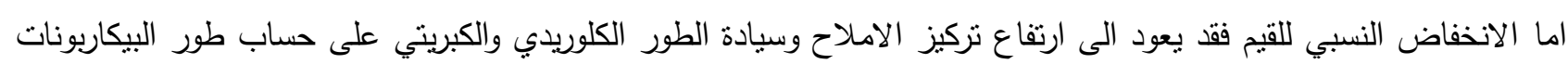

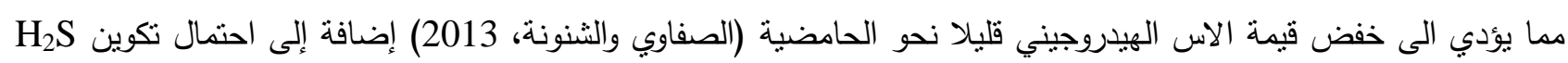
من عمليات الاكسدة والاختزال في الظروف اللاهوائية Anoxic Condition لأيونات الكبريتات والذي تأكسد عند تعرضية لإنية للأوكسجين الى حامض الكبريتيك (الصفاوي والمعاضيدي، 2013). وعموماً فإن مياه الآبار المدروسة هي ضمن الحئن الحدود المناسبة

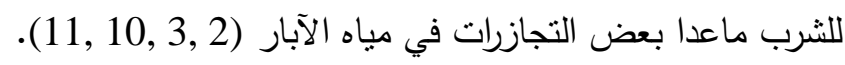

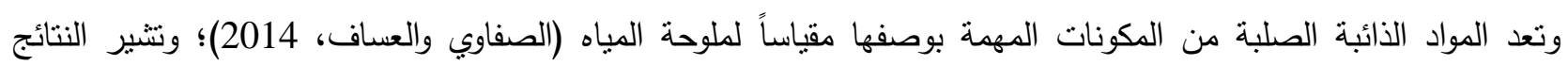

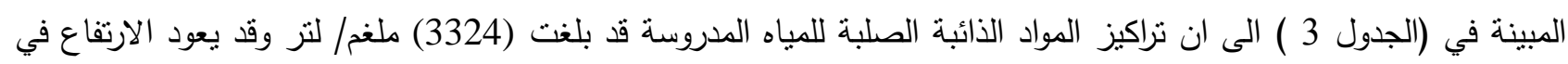
التراكيز الى طبيعة التكوينات الجيولوجية التي تتضمن تكوين الفتحة وقوامه املاح المنبخرات والجبس والدولومايت وتككوين إنجانة المتكون من تعاقبات من حجر الرمل والغرين والطفل، وهذه الاختلافات تتعكس على نوعية المياه المارة خلالها، وهذه النتائج مقاربة للنتائج التي نوصل اليها الصفاوي (2007) عند دراسته للمياه الجوفية لقرية الكونسية، ناحية حميدات والتي بلغت (2944)

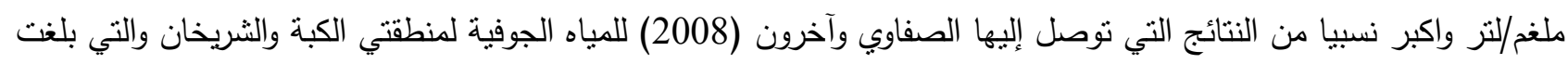

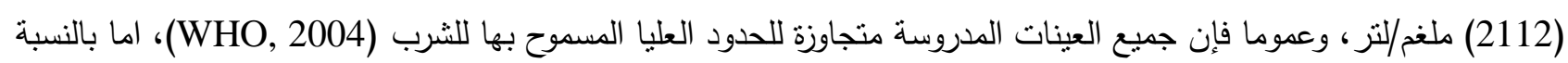
لتركيز القاعدية فهي تؤدي دورا في معادلة الحموضة او ما يسمى (ANC) عند تكونها ولولا هذه القابلية لكانت التأثيرات السلبية

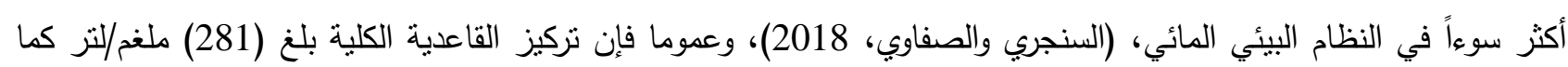
مبين في (الجدول 3) وهذا الارتفاع النسبي في التركيز يعود الى التفاعلات التي تحدث في المياه خلال مرورها في التكوينات الجيولوجية كما في المـعادلات الآتية:

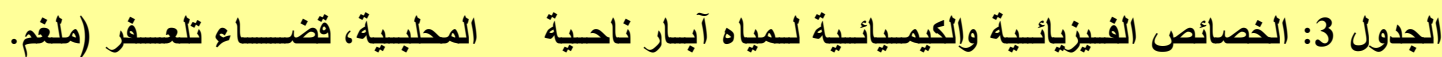




\begin{tabular}{|c|c|c|c|c|c|c|c|c|c|c|c|c|c|}
\hline \multicolumn{14}{|c|}{ لتر -1). } \\
\hline $\mathrm{PO}_{4}$ & $\mathrm{SO}_{4}$ & $\mathrm{Cl}$ & $\mathrm{HCO}_{3}$ & K & $\mathrm{Na}$ & $\mathrm{Mg}$ & $\mathrm{Ca}$ & T.H & Alk & TDS & $\mathrm{pH}$ & \multicolumn{2}{|c|}{ Well NO. } \\
\hline 0.023 & 857 & 33 & 192 & 4.6 & 40 & 77 & 373 & 1370 & 157 & 1087 & 6.36 & Min. & \\
\hline 2.310 & 1971 & 64 & 222 & 11.4 & 60 & 107 & 641 & 1920 & 182 & 2694 & 7.13 & Max. & 1 \\
\hline 0.609 & 1448 & 48 & 205 & 7.7 & 47 & 89 & 556 & 1731 & 168 & 2224 & ---- & mean & \\
\hline 0.029 & 1697 & 30 & 183 & 3.1 & 52 & 91 & 611 & 1900 & 150 & 1830 & 6.35 & Min. & \\
\hline 0.096 & 2154 & 107 & 257 & 3.6 & 60 & 114 & 661 & 2120 & 211 & 3118 & 7.17 & Max. & 2 \\
\hline 0.063 & 1973 & 63 & 236 & 3.3 & 57 & 102 & 640 & 2020 & 193 & 2401 & ---- & mean & \\
\hline 0.013 & 1152 & 39 & 178 & 10 & 33 & 66 & 601 & 1850 & 146 & 1715 & 6.33 & Min. & \\
\hline 0.150 & 1760 & 90 & 199 & 21 & 67 & 97 & 649 & 2020 & 163 & 2976 & 7.35 & Max. & 3 \\
\hline 0.074 & 1557 & 72 & 190 & 16 & 54 & 87 & 636 & 1947 & 156 & 2417 & ---- & mean & \\
\hline 0.000 & 1462 & 36 & 199 & 20 & 57 & 101 & 591 & 1950 & 163 & 2616 & 6.81 & Min. & \\
\hline 0.050 & 1880 & 118 & 273 & 30 & 100 & 117 & 661 & 2120 & 224 & 3210 & 7.04 & Max. & 4 \\
\hline 0.027 & 1670 & 88 & 242 & 26 & 85 & 111 & 625 & 2012 & 198 & 2975 & ---- & mean & \\
\hline 0.071 & 939 & 21 & 160 & 9.1 & 15 & 97 & 353 & 1470 & 131 & 1536 & 6.68 & Min. & \\
\hline 0.154 & 1763 & 78 & 266 & 9.6 & 31 & 122 & 625 & 2000 & 218 & 2982 & 7.25 & Max. & 5 \\
\hline 0.097 & 1334 & 35 & 188 & 9.3 & 25 & 112 & 557 & 1878 & 154 & 2407 & ---- & mean & \\
\hline 0.042 & 1245 & 15 & 142 & 12,6 & 17 & 78 & 457 & 1060 & 116 & 1715 & 6.5 & Min. & \\
\hline 0.150 & 1860 & 74 & 270 & 27.0 & 43 & 140 & 600 & 2000 & 221 & 3134 & 7.38 & Max. & 6 \\
\hline 0.074 & 1579 & 35 & 170 & 15.9 & 32 & 113 & 511 & 1736 & 139 & 2676 & ---- & mean & \\
\hline 0.040 & 1168 & 20 & 161 & 2.9 & 27 & 105 & 531 & 1940 & 132 & 1942 & 6.5 & Min. & \\
\hline 0.059 & 2085 & 41 & 190 & 9.1 & 31 & 180 & 621 & 2133 & 156 & 2842 & 7.14 & Max. & 7 \\
\hline 0.050 & 1619 & 28 & 170 & 4.5 & 29 & 145 & 595 & 2001 & 139 & 2554 & ---- & mean & \\
\hline 0.025 & 1607 & 18 & 150 & 2.5 & 17 & 88 & 491 & 1940 & 123 & 2742 & 6.89 & Min. & \\
\hline 0.960 & 2172 & 31 & 184 & 11 & 68 & 176 & 632 & 2000 & 151 & 2966 & 7.21 & Max. & 8 \\
\hline 0.050 & 1823 & 24 & 181 & 5.0 & 41 & 124 & 581 & 1963 & 134 & 2857 & ---- & mean & \\
\hline 0.021 & 1652 & 33 & 181 & 2.8 & 31 & 92 & 581 & 2000 & 148 & 2862 & 6.66 & Min. & \\
\hline 0.037 & 2096 & 73 & 244 & 11 & 36 & 134 & 648 & 2100 & 200 & 3068 & 7.05 & Max. & 9 \\
\hline 0.028 & 1903 & 47 & 205 & 5.7 & 33 & 117 & 621 & 2033 & 168 & 2956 & ---- & mean & \\
\hline 0.114 & 1629 & 58 & 161 & 40 & 52 & 105 & 734 & 1060 & 132 & 2502 & 6.41 & Min. & \\
\hline 0.640 & 2261 & 148 & 34 & 50 & 94 & 126 & 673 & 2180 & 281 & 3390 & 7.02 & Max. & 10 \\
\hline 0.269 & 1977 & 105 & 242 & 45 & 78 & 119 & 655 & 1874 & 198 & 2859 & ---- & mean & \\
\hline 0.033 & 1565 & 55 & 156 & 2.5 & 43 & 102 & 611 & 2000 & 128 & 2873 & 6.43 & Min. & \\
\hline 0.087 & 2074 & 164 & 257 & 3.2 & 57 & 131 & 649 & 2100 & 211 & 3324 & 7.60 & Max. & 11 \\
\hline 0.053 & 1782 & 90 & 205 & 2.8 & 50 & 116 & 628 & 2044 & 168 & 3018 & ---- & mean & \\
\hline 0.038 & 1623 & 24 & 160 & 6.8 & 28 & 102 & 592 & 1900 & 131 & 2702 & 6.88 & Min. & \\
\hline 0.500 & 2000 & 25 & 177 & 9.5 & 31 & 122 & 611 & 1980 & 145 & 2808 & 7.31 & Max. & 12 \\
\hline 0.172 & 1869 & 25 & 167 & 8.4 & 30 & 111 & 598 & 1949 & 137 & 2744 & ---- & mean & \\
\hline 10 & 400 & 250 & 200 & 12 & 200 & 150 & 200 & 500 & 150 & 1000 & $9-6.5$ & Stand. & imit* \\
\hline
\end{tabular}

*Standard limit for drinking (WHO, 2004)

$$
\text { (الصفاوي وطلعت، 2018) : (المب ) }
$$

$\mathrm{CO}_{2}+\mathrm{H}_{2} \mathrm{O} \rightarrow \mathrm{H}_{2} \mathrm{CO}_{3}$

$\mathrm{CaCO}_{3}+2 \mathrm{H}_{2} \mathrm{CO}_{3} \rightarrow \mathrm{Ca}\left(\mathrm{HCO}_{3}\right)_{2}$

وعلى الرغم من كون القاعدية ليس لها تأثثرات ضارة على الصحة العامة الا ان التراكيز المرتفعة تعطي للماء طعما غير

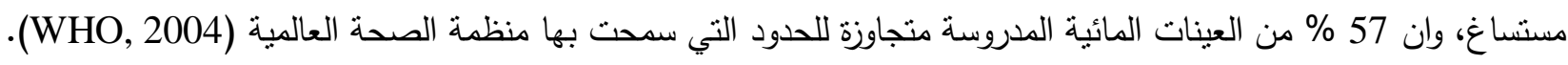
اما بالنسبة للعسرة الكلية للمياه فإنها تؤدي دورا واقيا للتخفيف من التأثيرات السمية لبعض المبات المواد السامة كالعناصر المعدنية السامة

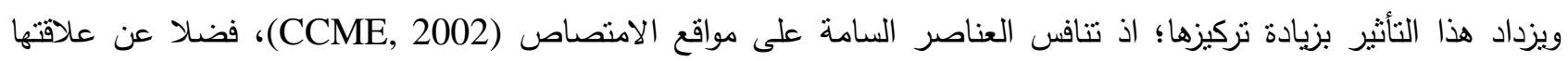


بالحفاظ على تركيب الاحماض النووية وعمليات الاستتساخ والتصحيح لـ DNA وتثبيط ميكانيكية تأثثر بعض المواد المسرطنة في جسم الكائن الحي (Al-Saffawi, 2018b). ونتشير النتائج المبينة الجدول (3) الى ان نراكيز العسرة الكلية وأيونات الكالسيوم

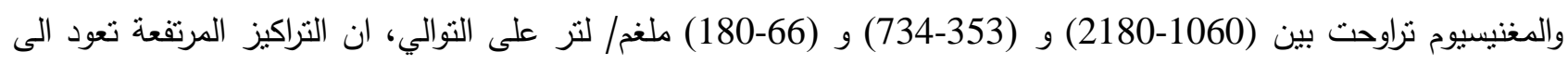

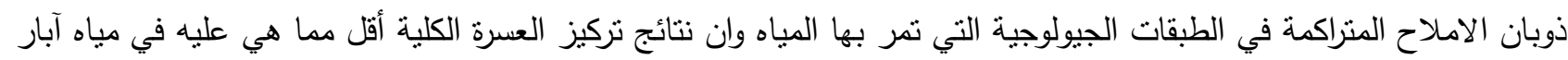
قرية قرة تبة الني نراوحت بين (2490-2562) ملغم/ لتر (المشهداني وجماعته، 1989)، وعموما فإن قيم العسرة الكلية لمنطقة

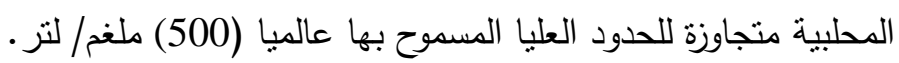
اما بالنسبة لأيوني الصوديوم والبوتاسيوم فان ايون الصوديوم يوجد بنسبة أكبر من البوتاسيوم في مياه العراق الطبيعية، وأنّ

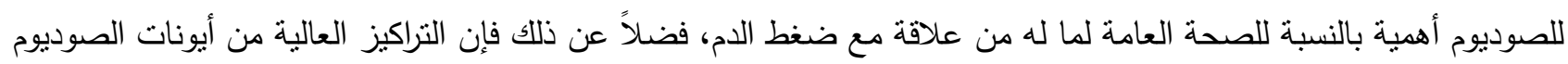

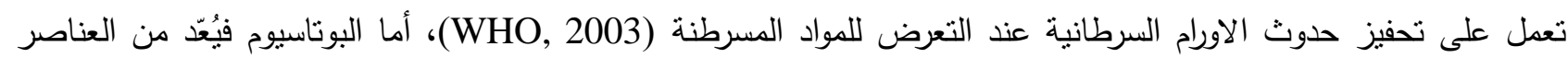

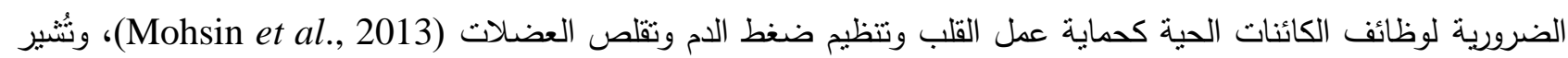
النتائج المبينة في (الجدول 3) إلى أن نركيز ايونات الصوديوم والبوتاسيوم تراوحت بين (15-100) و (2.5-50) ملغم/ لنر على فئل

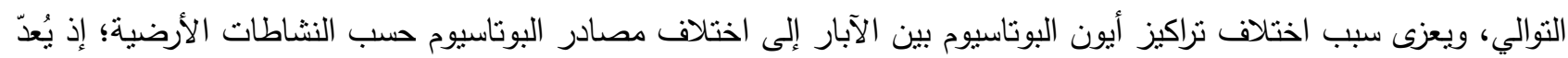

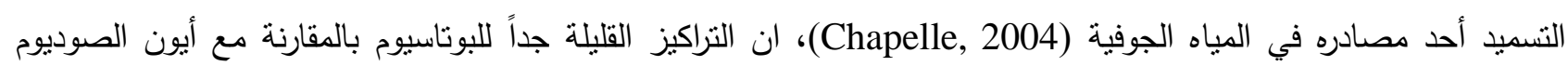
وعلى الرغم من وجودهما في القشرة الأرضية بكميات منقاربة يعود إلى الانتقالية العالية للصوديوم والاستقرارية النسبية للبوتاسيوم نتيجة دخوله في تركيب المعادن الطينية في أثثاء عملية التجوية (الصفاوي والثنونة، 2013)، وتتواجد أيونات الكلوريدات والكبريتات في المياه الطبيعية ويعتمد تراكيزها على طبيعة التكوينات الجيولوجية والصخور التي مرت بها المياه، فارتفاع تركيزهما المتجاوزة للحدود المسموح بها لها نأثيرات سلبية في نوعية مياه الثرب، كما تسبب الكبريتات الطعم المر Bitter taste للمياه عند فيداه

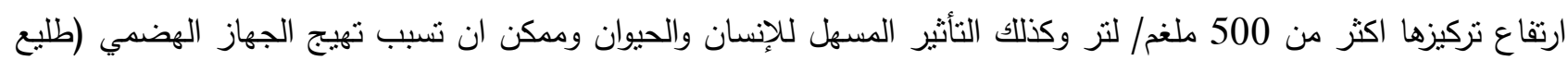
وآخرون، 2002؛ Kumar et al., 2015 )، ويلاحظ من الجدول بأن تركيز ايونات الكلوريد ضمن الحدود المسموح بها عالميا

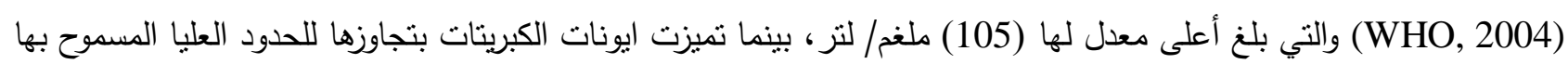
للشرب حيث تراوحت معدلاتها بين (1334-1977) ملغم/ لتر وهذا الارتفاع بالتزكيز يعود الى طبيعة التكوينات الجيولوجية التي تمر بها المياه.

اما بالنسبة لايونات الفوسفات $\mathrm{PO}_{4}$ تسبب مشاكل في الجهاز الهضمي (Al-Saffawi and Al-Sardar, 2018) وتتثبر النتائج المبينة في الجدول الى انخفاض ماض محتوى الآبار المدروسة من ايونات الفوسفات الذي تراوح بين (0.00 -0.50) ملغم/لتز ويلاحظ ايضا انخفاض تراكيز الفوسفات

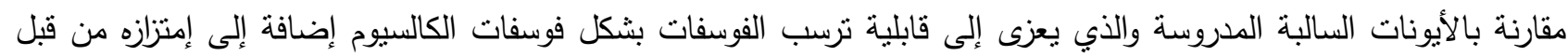

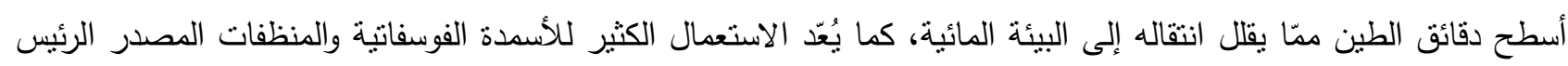
للفوسفات في المياه الجوفية (الصفاوي والثنونة، 2013)، وعموما فإن تركيز ايونات الفوسفات تعد ضمن الحدود المسموح بها للشرب التي حددتها منظمة WHO.

\section{تقييم مياه الآبار للشرب باستخدام (WQI)}

ان الهدف الرئيس من حساب دليل نوعية المياه هو لتسهيل الحكم على نوعية المياه بوساطة تحويل الكم الهائل من بأن

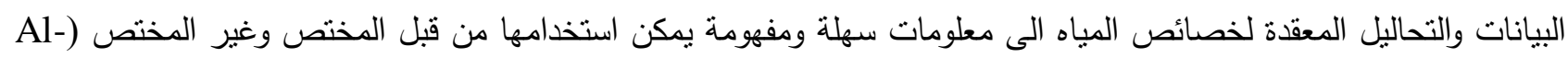

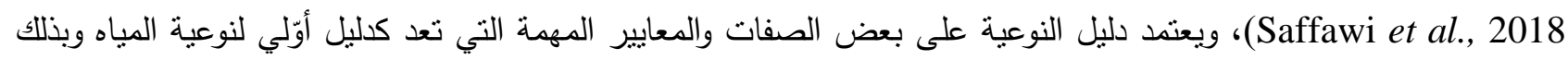
يعطي فكرة عامة عن المشاكل المحتملة للمياه في أية منطقة (Etim et al., 2013). ونم تصنيف نوعية مياه آبار ناحية المحلبية 


$$
\text { عبدالعزيز يونس طليع الصفاوي }
$$

كما مبين في الجدول (4) الذي يشير الى ان قيم دليل نوعية المياه متراوحة بين (42.41-60.45) وكذلك فان 83\% من

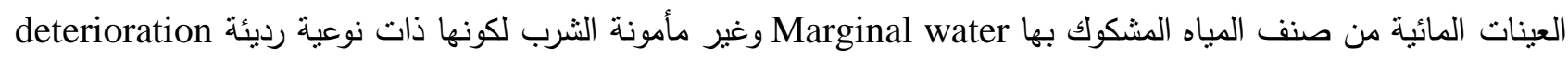
إذ هي متجاوزة للمستويات المسموح بها (WHO, 2004)، اما بقية العينات المائية المتمتلة بمياه البئر ذات نوعية فقيرة Poor quality وغير مناسبة للشرب وهذا التردي في نوعية المياه يعود بالدرجة الاساسية الى التراكيز المرتفعة

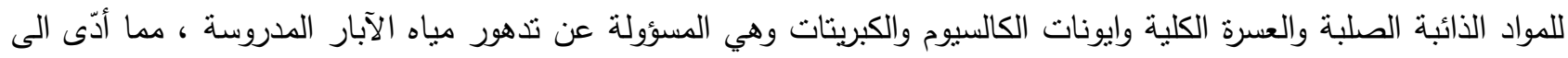
ارتفاع العوامل F3, F2, F1 وبالتالي انعكست على خفض قيم وائنات مؤشر النوعية.

\begin{tabular}{|c|c|c|c|c|c|c|}
\hline \multicolumn{7}{|c|}{ لجدول 4: قيم وتصنيف نوعية مياه آبار ناحية المحلبية للشرب. } \\
\hline \multicolumn{3}{|c|}{ CCME,WQI } & \multirow{2}{*}{$\mathrm{F}_{3}$} & \multirow{2}{*}{$\mathrm{F}_{2}$} & \multirow{2}{*}{$\mathrm{F}_{1}$} & \multirow{2}{*}{ الابار } \\
\hline & & 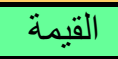 & & & & \\
\hline Marginal & مشكوك فيه & 46. 77 & 46.34 & 58.10 & 54.55 & 1 \\
\hline Marginal & مشكوك فيه & 48.00 & 51.32 & 50.00 & 54.55 & 2 \\
\hline Poor & رديئة النوعية & 44.30 & 47.00 & 55.17 & 63.64 & 3 \\
\hline Marginal & مشكوك فيه & 45.35 & 53.49 & 55.88 & 54.55 & 4 \\
\hline Marginal & مشكوك فيه & 56.47 & 44.57 & 40.38 & 45.45 & 5 \\
\hline Marginal & مشكوك فيه & 47.70 & 46.76 & 55.10 & 54.55 & 6 \\
\hline Marginal & مشكوك فيه & 51.63 & 46.76 & 43.18 & 54.55 & 7 \\
\hline Marginal & مشكوك فيه & 52.82 & 47.14 & 38.46 & 54.55 & 8 \\
\hline Marginal & مشكوك فيه & 52.90 & 50.03 & 42.42 & 45.45 & 9 \\
\hline Poor & رديئة النوعية & 42.41 & 54.46 & 54.17 & 63.64 & 10 \\
\hline Marginal & مشكوك فيه & 51.37 & 50.50 & 48.89 & 54.55 & 11 \\
\hline Marginal & مشكوك فيه & 60.45 & 48.45 & 34.88 & 36.36 & 12 \\
\hline
\end{tabular}

الاستنتاجات والتوصيات

1. تميزت المصـادر المائيسه المدروسـة بارتفاع أغلب المعـايير المدروسـة وبخاصـة تراكيز الامـلاح الذائبـة الصلبة والعسـرة الكليـة وتركيز ايونات الكالسيوم والكبريتات التي جاوزت الحدود القياسية المسموح بها للشرب؛ اذ ان هناك 235 اختباراً متجاوزة للحدود المسموح بها للشرب من مجموع 527 اختباراً مما جعل المياه متدهورة النوعية. 2. نوعية مياه الابار المدروسة حسب تصنيف معامل النوعية (WQI) تتردّد مابين مشكوك بهاه

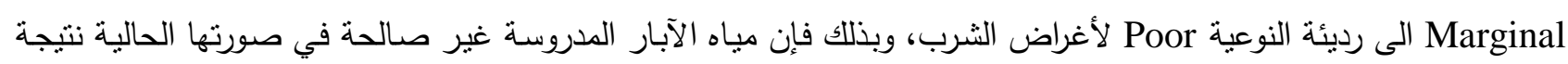
لانحرافها عن المستويات الطبيعية وفي ضـوء ذلك فإن البحث يوصي بإجراء بعض الاجراءات البسيطة لتحسين نوعيتها كعمليات التجميد الجزئي للميـاه والتخلص من الماء غير المتجمد الذي يتركز فيه معظم الاملاح واستخدام الجزء المتجمد بعد اذابته للشرب حيث يشير الصفاوي

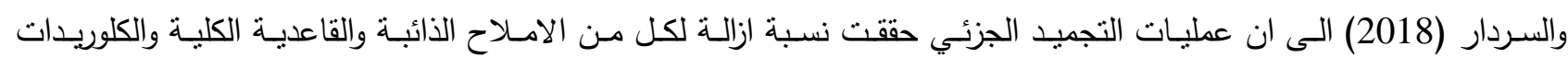
والكبريتات إلى (56 - 55 - 42 - 85 \% على على التوالي. 


\section{المصادر العريية}

السردار، نور ميسر ؛ الصفاوي، عبدالعزيز يونس طليع ؛ الثنونة، ريم عدنان (2018). تقييم خصائص نوعية المياه وحساب المبابه

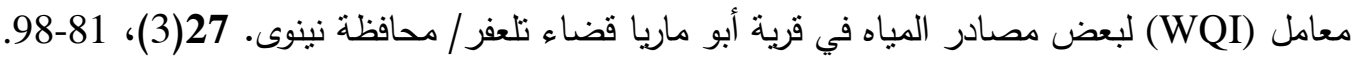

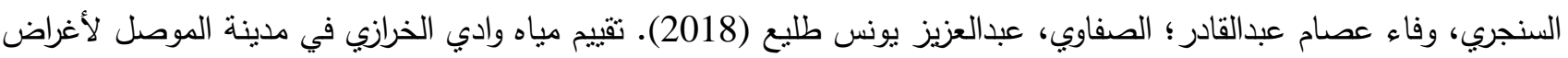

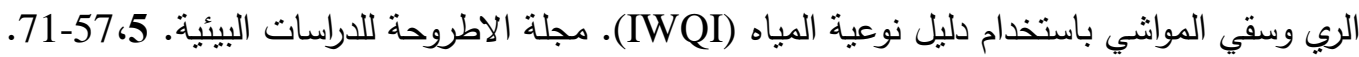
الصفاوي، عبد العزيز يونس طليع (2007). دراسة صلاحية المياه الجوفية، ناحية حميدات للأغراض الزراعية. مجلة التربية والعلم. 20(1)، 191-204.

الصفاوي، عبد العزيز يونس طليع؛ طلعت، ريم أياد (2018). تنقية مياه الصرف الصحي بالتعريض المباشر للأشعة الثمسية. مجلة علوم الرافدين 27(1)، 64-75.

الصفاوي، عبدالعزيز يونس طليع؛ السردار، نور ميسر (2018). إمكانية استخدام بعض الطرائق الفيزياوية والحيوية لتحسين نوعية مياه الآبار • مجلة التربية والعلم للعلوم الصرفة. 27(9)، 47-60. الصفاوي، عبدالعزيز يونس طليع؛ الثنونة، ريم عدنان عبدالرزاق (2013). دراسة بيئية وبكتريولوجية لنوعية المياه الجوفية جنوب

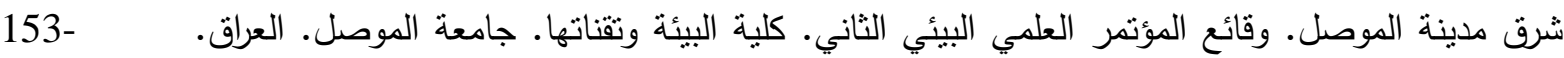

الصفاوي، عبدالعزيز يونس طليع؛ العساف، ازهار يونس (2014). دراسة بيئية وبيولوجية للفضلات السائلة في وادي الدانفيلي وتاثيره على نوعية مياه نهر دجلة جنوب مدينة الموصل. مجلة التربية والعلم للعلوم الصرفة.

$.89-71 ،(1) 27$

الصفاوي، عبدالعزيز يونس طليع؛ العساف، ازهار يونس رضا (2018). التقييم النوعي لمياه نهر دجلة باستخدام معامل نوعية المياه (WQI) لاغراض الثرب في محافظة نينوى. شمال العراق. قيد النشر في مجلة الدراسات البيئية، جامعة

سوهاج.

الصفاوي، عبدالعزيز يونس طليع؛ المعاضيدي، علاء طلعت حسين (2018). استخدام صفائح الالمنيوم كعاكسات في معالجة مياه المجاري بالأشعة الثمسية. مجلة التربية والعلم للعلوم الصرفة. 27(3)،1-18. صفاوي، عبدالعزيز يونس طليع؛ المعاضيدي، علاء طلعت حسين (2013). الواقع البيئي لوادي عكاب وتأثيره على مياه نهر دجلة شمال مدينة الموصل.العراق. مجلة الدراسات البيئية (JES). 12 ، 55-61. طليع، عبدالعزيز يونس؛ ابراهيم، ضياء ايوب؛ الصفاوي، نوار طلال (2002). دراسة نوعية المياه الجوفية لقرية الكونسية وصلاحيتها للاستخدامات المنزلية. مجلة التربية والعلم. 14(2)،19-29. المشهداني، يحيي داوود؛ طليع، عبدالعزيز يونس؛ الحفوظي، سعد الدين ماجد (1989). المياه الجوفية الممتدة بين مدينة الموصل وناحية بعثيقة ومدى صلاحيتها للاستخدامات المدنية والزراعية. مجلة التربية والعلم. 9،11-21. الصفاوي، عبدالعزيز يونس طليع؛ علي، فائق حس؛ كنة، عبدالمنعم محمد علي (2008). التقييم الفيزيائي والكيميائي لبعض وآبار منطقة الثريخان- الكبة وصلاحيتها للشرب والاستخدامات المنزلية. المؤتمر العلمي السادس لمركز الموارد المائية، 27 - 28 نترين الأول 2008 جامعة الموصل. 193-201. قبلان، عبدالباري يونس حسين ؛الحمداني، ابراهيم عمر سعيد ؛الصفاوي، عبدالعزيز يونس طليع (2018). تطبيق الموديل الكندي لتقييم الواقع البيئي لمياه الآبار للأغراض الثرب والاستخدامات المنزلية في الجانب الايسر من مدينة

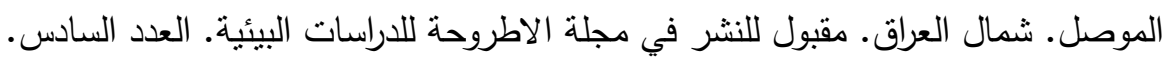




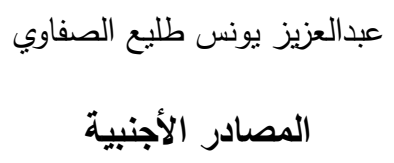

Al- Saffawi, A.A.T.; Al-Sardar, N.M.S. (2018). Assessment of groundwater quality status by using water quality index in Abu-Jarboaa and Al-Darrawesh Villages, Basiqa district. Iraq. Int. $J$. Enhanced Res. in Sci., Techn. and Engin. 7(6), 6 - 12.

Alsaffawi, A.Y.T. (2018a).Application of CCME WQI to Assessment the Environmental Status of Tigris River Water for Quatic Life within Nineveh Governorate, North Iraq. Al-utroha J. for Environ. Sci. 5, 13-25.

Al-Saffawi, A.Y.T.(2018b). Water quality index assessment of ground water in Al- Nimrud district of Southeastern Mosul City. Iraq. Sent to publication in: Pakistan J. Analytical Chem. and Environ.

Al-Saffawi, A.Y.T.; Al-Molaa, Y.T.M. (2018c). Quality characterization of groundwater by using water quality index in Al- Kasik district Northeastern of Mosul City. Iraq. Sent to publication in: Int. J. Enhanced Res. in Sci., Techn.and Engin.

APHA, A.W. (1998). "Standard Method for Examination of Water and Wastewater". 20 $0^{\text {th }}$ ed., Washington, DC, USA.

Canadian Council of Ministers of the Environment (CCME), (2001). Canadian Water Quality Guidelines for the Protection of Aquatic Life: CCME Water Quality Index.: (2001). Technical Report، Canadian Council of Ministers of the environment winnipeg, MB, Canada. Available at: http://www.ccme.ca/sourcetotap/wqi.html.

Chapelle, F.H. (2004). Geochemistry of groundwater. In Holland, H.D. and Turkian, K.K. Treaties of Geochemistry. Surface and groundwater, Weathering and Soils. 5,425-449.

Etim, E.E.; Odoh, R.; Itodo, A.U.; Umoh, S.H.; Lawal, U.(2013). Water quality index for the assessment of water quality from different sources in the Niger Delta region of Nigeria. Frontiers in Sci. 3(3),89-95.

Krishan, G.; Singh, S.; Kumar, C.P.; Garg, P.K.; Gurjar, S.; Ghosh, N.C.; Chaudhary, A. (2016). Assessment of groundwater quality for drinking purpose by using water quality index (WQI) in Muzaffarnagar and Shamli districts. Uttar Pradesh, India. Hydrol. Current Res. 7(1),1-4. http://dx.doi.org/10.4172/2157-7587.1000227

Kumar, S.K.; Logeshkumaran, A.; Magesh, N.S.; Prince, S.; Godson, P.S.; Chandrasekar, N. (2015).Hydro- geochemistry and application of water quality index (WQI) for ground water quality assessment, Anna Nagar, part of Chennai City, Tamil Nadu, India. Appl. Wat. Sci. 5, 335-343.

Kumar, M.K., Mahesh, M.K.; Sushmitha, B.R. (2014). CCME water quality index and assessment of physico- chemical parameters of chikkakere,periyapatna, Mysore district, Karnataka state, India. Int. J. Innov. Res. in Sci., Engn. and Techn. 3(8),15343-15347.

Mohsin, M.; Safdar, S.; Asghar, F.; Jamal, F. (2013). Assessment of drinking water quality and its impact on residents health in Bahawalpur city. Pakistan. Int. J. Humanit. and Social Sci., 3(15), 114-128.

Reed, R.H.; Mani, S.K.; Meyer, V. (2000). Solar photo- oxidative disincentive of drinking water: preliminary field observations. Applied Micro. 30, 432-436.

Rojko, C. (2003). Solar disinfection of drinking water. Msc. Thesis Coll. of Engineering, U. S. A.

Salman, J.M.; Abd- Al-Hussein, N.A.; Al-Hashimi, O.A. (2015). Assessment of water quality of Hilla river for drinking water purpose by Canadian index (CCME.WQI). Int. J. Rece. Sci. Res. 6(2), 2746-2749.

UNEP, (2008). An Overview of the State of the World's Fresh and Marine Waters - 2nd Edition - 2008 [online] [Accessed April 15 2015]. Available at: http://www.unep.org/dewa/vitalwater/article186.html.

Water Aid, (2016).Nigeria [online]. Available at: zttp://www. wateraid.org/ng.

WHO. (2004). "Guidelines for Drinking-water Quality". $3^{\text {rd }}$ ed. Volume 1: Recommendations. World Health Organization, Geneva.

WHO. (2003). "Sodium in Drinking Water, Guide for Drinking Water Quality". World health organization. Geneva. Swizerland, 11. 